\title{
Fabrication, characterization and photocatalytic properties of CdS nanoparticles modified by $\mathrm{N}$-doped $\mathrm{TiO}_{2} \mathrm{NTs}$
}

\author{
Dawei GaO ${ }^{1, *}$, ChunXia WAng ${ }^{1}$, Yu Jian ${ }^{1}$, Weiwei Li ${ }^{1}$, Pengyu Dong $^{2}$ \\ ${ }^{1}$ College of Textiles and Clothes, Yancheng Institute of Technology, \\ Yancheng 224051, P.R. China \\ ${ }^{2}$ Key Laboratory for Advanced Technology in Environmental Protection of Jiangsu Province, Yancheng Institute of \\ Technology, Yancheng 224051, P.R. China
}

\begin{abstract}
Highly ordered $\mathrm{TiO}_{2}$ nanotube arrays $\left(\mathrm{TiO}_{2} \mathrm{NTs}\right)$ were prepared by anodic oxidizing method on a surface of Ti substrate. Fabrication of nitrogen-doped $\mathrm{TiO}_{2}$ nanotube arrays $\left(\mathrm{N}-\mathrm{TiO}_{2} \mathrm{NTs}\right)$ was carried out by immersion in ammonia solution. CdS nanoparticles loaded $\mathrm{N}$-doped $\mathrm{TiO}_{2}$ nanotube arrays $\left(\mathrm{CdS} / \mathrm{N}-\mathrm{TiO}_{2} \mathrm{NTs}\right)$ were obtained by successive ionic layer adsorption and reaction (SILAR) technique. The samples were characterized by X-ray diffraction (XRD), X-ray photoelectron spectroscopy (XPS), field emission scanning electron microscopy (FE-SEM), transmission electron microscopy (TEM), high resolution transmission electron microscopy (HRTEM), photoluminescence (PL) emission spectra and ultraviolet-visible (UV-Vis) diffuse reflectance spectroscopy (DRS). The results indicate that the $\mathrm{TiO}_{2}$ nanotube diameter and wall thickness are $100 \mathrm{~nm}$ to $120 \mathrm{~nm}$ and $20 \mathrm{~nm}$ to $30 \mathrm{~nm}$, respectively. Moreover, the morphology and structure of the highly ordered $\mathrm{TiO}_{2} \mathrm{NTs}$ are not affected by $\mathrm{N}$-doping. Furthermore, CdS nanoparticles are evenly distributed on the surface of $\mathrm{TiO}_{2} \mathrm{NTs}$. Finally, the photocatalytic activity of $\mathrm{CdS} / \mathrm{N}-\mathrm{TiO}_{2} \mathrm{NTs}$ was evaluated by degradation of $\mathrm{MO}$ under visible-light irradiation. Compared with $\mathrm{TiO}_{2} \mathrm{NTs}$, $\mathrm{N}-\mathrm{TiO}_{2} \mathrm{NTs}, \mathrm{CdS} / \mathrm{N}-\mathrm{TiO}_{2} \mathrm{NTs}$ exhibited enhanced photocatalytic properties, and the highest degradation rate of

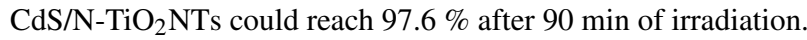

Keywords: $\mathrm{TiO}_{2}$ nanotube arrays; $\mathrm{N}$ dopants; $\mathrm{CdS}$ nanoparticles; visible light; photocatalysis

\section{Introduction}

Photocatalytic degradation of various organic and inorganic pollutants using semiconductor nanopowders has been intensively investigated [13]. Among various photocatalysts, $\mathrm{TiO}_{2}$ has been one of the most promising materials due to its nontoxicity, chemical inertness, photocatalytic activity and low cost $[4,5]$. However, the small surface area, poor photoresponse under visible light and the high rate of photogenerated electron/hole pair recombination among $\mathrm{TiO}_{2}$ nanoparticles are the main factors limiting further improvement of its photocatalytic efficiency.

Recently, varieties of $\mathrm{TiO}_{2}$ nanostructures, including nanorods, nanowires, nanobelts and nanotubes have been fabricated for degradation of organic pollutants. Among them, the $\mathrm{TiO}_{2}$ nanotube arrays $\left(\mathrm{TiO}_{2} \mathrm{NTs}\right)$ prepared by anodic oxidation

*E-mail: gdw8668@163.com method can be easily recovered and reused in waste water treatment. The tubes perpendicular to the $\mathrm{Ti}$ substrate form a Schottky-type contact and provide a unidirectional electric channel for the transport of photogenerated electrons [6]. Moreover, the aligned nanotube structure can reduce reflection of the light because of multiple radiation scattering by the nanotube walls [7].

However, due to its wide band gap $(3.2 \mathrm{eV}$ and $3.0 \mathrm{eV}$ for anatase and rutile phases, respectively), the photocatalytic activity of $\mathrm{TiO}_{2}$ is only limited in the UV region which is about $4 \%$ to $5 \%$ of the solar energy. Considerable attempts have been made to improve the visible light absorption of $\mathrm{TiO}_{2}$ by the substitutional non-metallic doping (N [8], C [9], S [10], etc.), novel metallic doping (Ag [11], Pt [12], Au [13], etc.) or depositing narrow-gap semiconductor materials (CdS [14], CdSe [15], CdTe [16], etc.). Among different nonmetal dopants, N-doping attracts much attention due to its atomic size comparable with oxygen, 
small ionization energy, metastable center formation and its stability [17]. Moreover, N-doping is considered as an ideal dopant due to the obvious reduction of the band gap of the $\mathrm{TiO}_{2}$ [18-20]. However, oxygen vacancies are usually generated by doping of $\mathrm{N}$ into the lattice of $\mathrm{TiO}_{2}$, which act as recombination centers and decrease the photocatalytic efficiency. To solve this problem, N-doped $\mathrm{TiO}_{2}$ modified with chalcogenide semiconductor was proposed. Compared with other semiconductors, CdS with a narrow band gap $(2.4 \mathrm{eV})$ and relatively high absorption coefficient in the visible region is highly desirable for the use in photocatalysis and solar cells $[21,22]$. The photogenerated electrons would move from $\mathrm{CdS}$ to $\mathrm{TiO}_{2}$ to restrain charge recombination in $\mathrm{TiO}_{2}-\mathrm{CdS}$ system, thereby, improving the photocatalytic activity of $\mathrm{TiO}_{2}$. Herein, we report a facile method to fabricate $\mathrm{CdS}$ nanoparticles modified $\mathrm{N}$-doped $\mathrm{TiO}_{2}$ nanotube arrays. The morphologies, structures, compositions and photocatalytic properties of as-prepared materials were studied.

\section{Experimental}

\subsection{Preparation of $\mathrm{CdS} / \mathrm{N}-\mathrm{TiO}_{2}$ NTs}

Ethanol, acetone, $\mathrm{HNO}_{3}, \mathrm{HCl}, \mathrm{HF}, \mathrm{NH}_{4} \mathrm{~F}$, $\mathrm{CdCl}_{2}, \mathrm{Na}_{2} \mathrm{~S}$, and ethylene glycol were purchased from Sinopharm Chemical Reagent Co., Ltd. All reagents were used without further purification.

A two-step anodization method was used to prepare $\mathrm{TiO}_{2}$ NTs on Ti substrate [6]. Titanium foils (99.8\% purity) with a size of $15 \mathrm{~mm} \times 15 \mathrm{~mm} \times 0.1 \mathrm{~mm}$ were ultrasonically cleaned for $10 \mathrm{~min}$ in water, acetone and ethanol, respectively. Then the titanium foils were anodized under $50 \mathrm{~V}$ for $1 \mathrm{~h}$ in ethylene glycol solution containing 0.5 wt. $\% \mathrm{NH}_{4} \mathrm{~F}$ and 2.5 vol. $\% \mathrm{H}_{2} \mathrm{O}$. The as-formed $\mathrm{TiO}_{2}$ NTs layer was peeled off by ultrasonication in deionized water to expose the Ti substrate. The second-step anodization was carried out in the mentioned electrolyte for $2 \mathrm{~h}$. After anodic oxidation, the samples were rinsed with ethanol for $5 \mathrm{~min}$. The as-prepared samples were immersed in $1 \mathrm{M} \mathrm{NH}_{3} \cdot \mathrm{H}_{2} \mathrm{O}$ solution for $12 \mathrm{~h}$ and annealed in a muffle furnace under ambient atmosphere at $450{ }^{\circ} \mathrm{C}$ for $1 \mathrm{~h}$ to obtain the $\mathrm{TiO}_{2}$ nanotubes [8].
$\mathrm{CdS}$ nanoparticles were deposited on $\mathrm{N}-\mathrm{TiO}_{2}$ NTs using SILAR process [14]. The as-prepared $\mathrm{N}-\mathrm{TiO}_{2} \quad \mathrm{NTs}$ were dipped into a $0.1 \mathrm{M} \mathrm{CdCl}_{2}$ aqueous solution for $1 \mathrm{~min}$, rinsed with deionized water, and then dipped for another 1 min into a $0.1 \mathrm{M} \mathrm{Na}_{2} \mathrm{~S}$ aqueous solution, and rinsed again with deionized water. The samples were denoted as $\mathrm{CdS} / \mathrm{N}-\mathrm{TiO}_{2}$ NTs.

\subsection{Characterization}

The morphologies of the samples were studied by field-emission scanning electron microscopy (FE-SEM, JOEL, JSM-6700F), and transmission electron microscopy (TEM, Philips, and CM120). The crystal structure of the samples was characterized by X-ray diffraction technique (MAC Science Co., Ltd. MXP 18 AHF, $\mathrm{CuK} \alpha, \lambda=0.15418 \mathrm{~nm}$ ). The surface chemical composition of the samples was analyzed by X-ray photoelectron spectroscopy (XPS, PHI Quantum 2000) with AlK $\alpha$ radiation source. All the binding energies were referred to the $\mathrm{C} 1 \mathrm{~s}$ peak at $284.8 \mathrm{eV}$ of the surface adventitious carbon. The photoluminescence (PL) emission spectra of the samples were measured at room temperature by Fluoromax-4 spectrofluorometer (USA) using $300 \mathrm{~nm}$ xenon lamp excitation. The UV-Vis diffuse reflectance spectra (DRS) of the samples were recorded by a UV-Vis spectrophotometer (UV-2550, Shimadzu). $\mathrm{BaSO}_{4}$ was used as a reflectance standard in the wavelength range of $300 \mathrm{~nm}$ to $800 \mathrm{~nm}$.

\subsection{Photocatalytic activity test}

The photocatalytic activity of the as-prepared samples was evaluated by photocatalytic decomposition of $30 \mathrm{~mL}$ methyl orange (MO, $10 \mathrm{mg} / \mathrm{L}$ ) aqueous solution under $250 \mathrm{~W}$ xenon lamp. The cut-off filters were used to obtain visible light $(\lambda>400 \mathrm{~nm})$. The suspension was constantly stirred in the dark for 15 min to achieve absorptiondesorption equilibrium. The concentration change of MO was monitored by determining the UV-Vis adsorption at $464 \mathrm{~nm}$ every $15 \mathrm{~min}$. After measurement, the photo-degradation experiments were continued on the sample as mentioned above. 


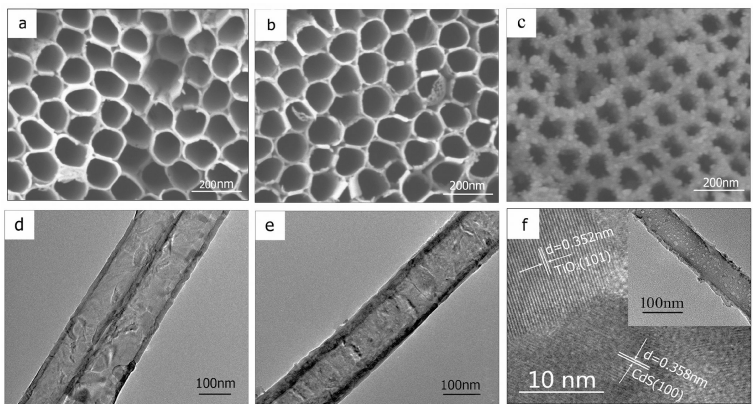

Fig. 1. SEM, TEM and HRTEM images of (a) and (d) $\mathrm{TiO}_{2} \mathrm{NTs}$, (b) and (e) $\mathrm{N}-\mathrm{TiO}_{2} \mathrm{NTs}$, (c) and (f) $\mathrm{CdS} / \mathrm{N}-\mathrm{TiO}_{2}$.

\section{Results and discussion}

Fig. 1 shows typical SEM and HRTEM images of both as-prepared samples. As shown in Fig. 1a and Fig. 1d, the samples consist of a well-aligned and vertical tubular structures with a diameter of $110 \mathrm{~nm}$ to $130 \mathrm{~nm}$ and wall thickness of $15 \mathrm{~nm}$. Fig. 1b and Fig. 1e indicate that the well-ordered porous structure was preserved, suggesting that $\mathrm{N}$-doping did not damage the ordered $\mathrm{TiO}_{2}$ nanotube arrays structure. Fig. 1c shows that the surface of the nanotubes has been successfully coated with a relatively uniform layer of $\mathrm{CdS}$ nanoparticles. Typical HRTEM and TEM (inset) images of $\mathrm{CdS} / \mathrm{N}-\mathrm{TiO}_{2}$ NTs are shown in Fig. 1d. The HRTEM image displays the lattice fringe with lattice spacing of $0.358 \mathrm{~nm}$, corresponding to the ( $\left.\begin{array}{lll}1 & 0 & 0\end{array}\right)$ lattice planes of CdS, as noted in Fig. 1d, what is in accordance with the results of XRD. The lattice with d spacing of $0.352 \mathrm{~nm}$, corresponding to the $\left(\begin{array}{lll}1 & 0 & 1\end{array}\right)$ plane of $\mathrm{TiO}_{2}$ can be found from HRTEM images [23].

Fig. 2 shows the XRD patterns of $\mathrm{TiO}_{2}$ NTs, $\mathrm{N}-\mathrm{TiO}_{2}$ NTs and $\mathrm{CdS} / \mathrm{N}-\mathrm{TiO}_{2}$ NTs. The patterns display two diffraction peaks at $40.5^{\circ}$ and $53.2^{\circ}$, corresponding to ( $\left.\begin{array}{llll}1 & 0 & 1\end{array}\right)$ and ( $\left(\begin{array}{lll}1 & 0 & 2\end{array}\right)$ crystal faces of Ti substrate, respectively. The characteristic peaks at $25.5^{\circ}, 37.1^{\circ}, 37.8^{\circ}, 48.2^{\circ}, 54.1^{\circ}, 55.2^{\circ}, 62.9^{\circ}$, $68.8^{\circ}$ and $70.6^{\circ}$ can be identified as the crystal planes of (1 $\left.\begin{array}{lll}1 & 0 & 1\end{array}\right),\left(\begin{array}{lll}0 & 0 & 4\end{array}\right),\left(\begin{array}{lll}1 & 1 & 2\end{array}\right),\left(\begin{array}{lll}2 & 0 & 0\end{array}\right),\left(\begin{array}{lll}1 & 0 & 5\end{array}\right)$, (2 11 1), (2 04 ), (1 116$)$ and (2 20 ) planes of anatase $\mathrm{TiO}_{2}$ (JCPDS Card No. 21-1272). The characteristic peaks that appeared at the $26.5^{\circ}$ and $43.8^{\circ}$ can be

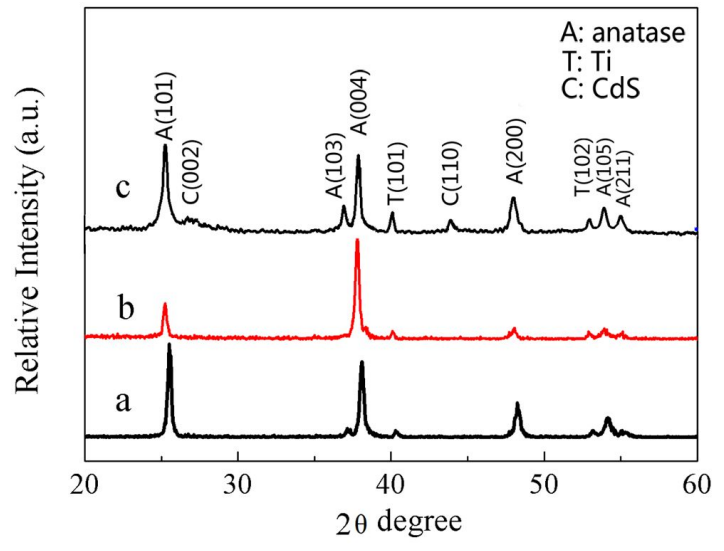

Fig. 2. XRD patterns of $\mathrm{TiO}_{2} \mathrm{NTs}(\mathrm{a}), \mathrm{N}-\mathrm{TiO}_{2} \mathrm{NTs}(\mathrm{b})$, $\mathrm{CdS} / \mathrm{N}-\mathrm{TiO}_{2}$ (c).

indexed as the CdS hexagonal structure with crystal faces of (llll $\left.0 \begin{array}{lll}0 & 2\end{array}\right)$ and $\left(\begin{array}{lll}1 & 1 & 0\end{array}\right)$, respectively (JCPDS Card No. 41-1049).

The average particle size was calculated using the Scherrer equation:

$$
d=0.89 \lambda / \beta \cos \theta
$$

where $\mathrm{d}$ is the crystal size, $\mathrm{k}$ is the constant (0.89), $\lambda$ is the X-ray wavelength $(1.54 \AA), \beta$ is the full width at half maximum (FWHM) of the peaks, $\theta$ is the diffraction angle. The crystallite sizes of $\mathrm{TiO}_{2}$ $\mathrm{NTs}, \mathrm{N}-\mathrm{TiO}_{2}$ NTs and $\mathrm{CdS} / \mathrm{N}-\mathrm{TiO}_{2}$ NTs, which have been calculated using anatase $\left(\begin{array}{lll}1 & 0 & 1\end{array}\right)$ diffraction peak, are $31.22 \mathrm{~nm}, 27.92 \mathrm{~nm}$ and $28.02 \mathrm{~nm}$, respectively. It shows that $\mathrm{CdS}$ modification had little effect on the crystallite sizes of $\mathrm{TiO}_{2}$, while the growth of $\mathrm{TiO}_{2}$ crystallites during calcination was strongly inhibited by N-doping.

The surface element composition and chemical states of $\mathrm{CdS} / \mathrm{N}-\mathrm{TiO}_{2} \mathrm{NTs}$ were analyzed by XPS, as shown in Fig. 3. Fig. 3a demonstrates the N1s XPS spectrum of the $\mathrm{CdS} / \mathrm{N}-\mathrm{TiO}_{2}$ NTs. The N1s peak at $399.8 \mathrm{eV}$ can be attributed to the oxidized nitrogen in the form of $\mathrm{O}-\mathrm{Ti}-\mathrm{N}$ linkage instead of molecularly chemisorbed $\mathrm{N}$ species on the surface of $\mathrm{TiO}_{2}$ NTs [16, 17]. In Fig. 3b, the binding energies of $458.2 \mathrm{eV}$ and $464.4 \mathrm{eV}$ are ascribed to the peaks of Ti $2 p_{3 / 2}$ and Ti $2 p_{1 / 2}$, respectively, which are ascribed to the titanium lattice in $\mathrm{TiO}_{2}$ with a $2 p_{3}$ binding energy of Ti (IV) ion. The peak shift 

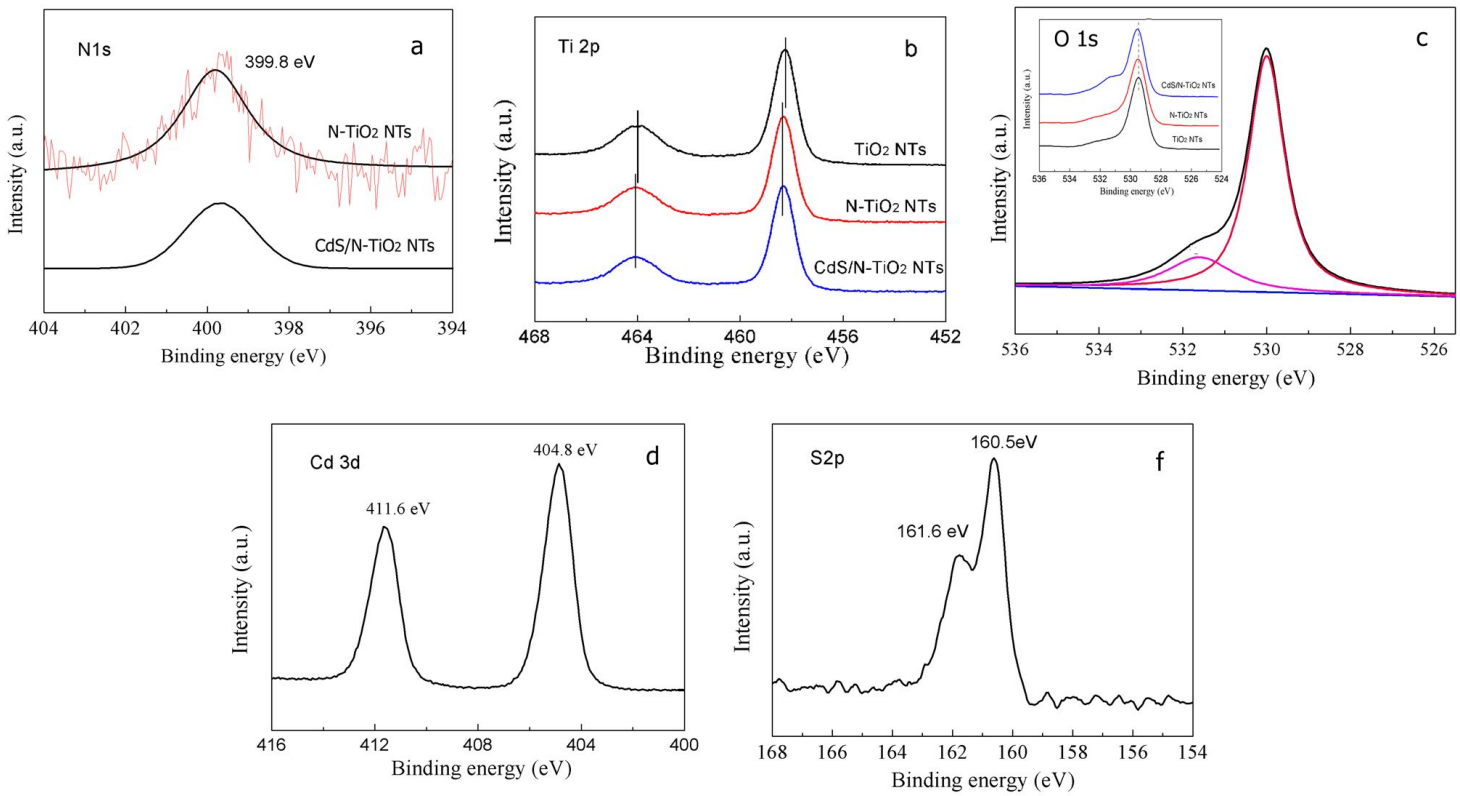

Fig. 3. XPS high resolution spectra of N1s (a), Ti2p (b), O1s (c), Cd 3d (d) and S 2p (e).

may contribute to the doping of $\mathrm{N}$ into the $\mathrm{TiO}_{2}$ lattice. The O1s XPS spectrum in Fig. 3c can be divided into two peaks centered at $531.1 \mathrm{eV}$ and $530.0 \mathrm{eV}$, respectively. Besides the presence of substitutional $\mathrm{N}$, it further confirms the formation of the O-Ti-N structure. The XPS spectrum of CdS3d in Fig. $3 d$ shows that the $3 d_{3 / 2}$ and $3 d_{5 / 2}$ signals are located at $411.6 \mathrm{eV}$ and $404.8 \mathrm{eV}$, respectively. The splitting of the $3 \mathrm{~d}$ doublet is $6.8 \mathrm{eV}$ which indicates that the $\mathrm{CdS}$ loading on the $\mathrm{TiO}_{2}$ surface exists as a form of $\mathrm{Cd}^{2+}$ [24]. As shown in Fig. 3e, binding energies of $160.5 \mathrm{eV}$ and $161.6 \mathrm{eV}$ are ascribed to the peaks of $S 2 p_{3 / 2}$ and $S 2 p_{1 / 2}$, respectively. The $2 \mathrm{p}$ splitting of $1.1 \mathrm{eV}$ between $\mathrm{S} 2 \mathrm{p}_{3 / 2}$ and $\mathrm{S} 2 \mathrm{p}_{1 / 2}$ confirms the $\mathrm{S}^{2-}$ state [25].

Herein, PL analysis was used to reveal the efficiency of charge carrier trapping, transfer, and separation and to investigate the fate of photogenerated electrons and holes in semiconductors [29]. Fig. 4 shows a comparison of fluorescence emission spectra of $\mathrm{TiO}_{2}$ NTs, N-TiO 2 NTs and $\mathrm{CdS} / \mathrm{N}-\mathrm{TiO}_{2} \mathrm{NTs}$ within the range of $350 \mathrm{~nm}$ to $550 \mathrm{~nm}$. It can be seen that all the samples show the similar PL spectra with peaks centered at $400 \mathrm{~nm}$ and $470 \mathrm{~nm}$, respectively. The peak located at about $400 \mathrm{~nm}$ is related to the electron transi-

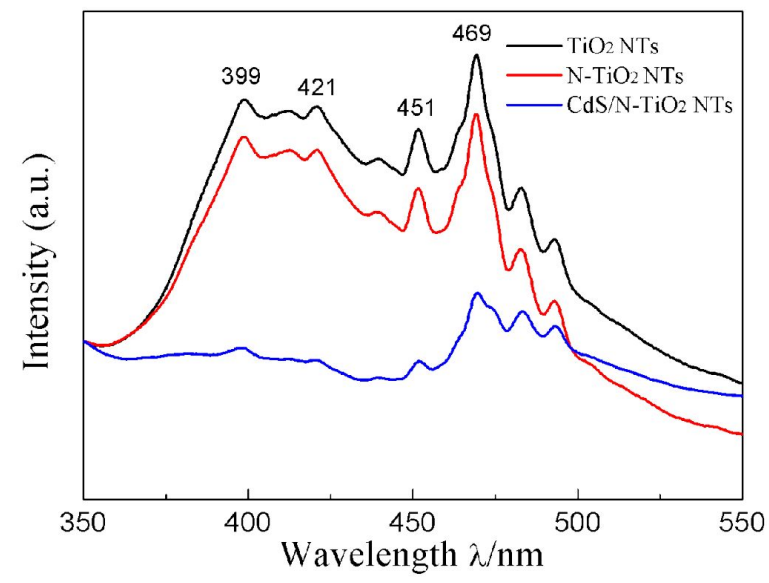

Fig. 4. Photoluminescence emission spectra of the samples.

tion from the valence band to conduction band, so-called self-trapped excitons, while the peak at $470 \mathrm{~nm}$ can be ascribed to surface oxygen vacancies located at the surface of $\mathrm{TiO}_{2}$ NTs. From the results, the PL intensity of $\mathrm{N}$-doped $\mathrm{TiO}_{2} \mathrm{NTs}$ is lower than that on $\mathrm{TiO}_{2} \mathrm{NTs}$, indicating that $\mathrm{N}$-doping markedly enhances the charge separation of photogenerated carriers of $\mathrm{TiO}_{2}$ NTs. In comparison with $\mathrm{N}_{-} \mathrm{TiO}_{2} \mathrm{NTs}$, the intensities of the PL 
emission of the $\mathrm{CdS} / \mathrm{N}-\mathrm{TiO}_{2}$ NTs samples are much lower, which indicates relatively lower recombination of excited electrons and holes. The peak intensity of $\mathrm{CdS} / \mathrm{N}-\mathrm{TiO}_{2}$ nanotubes decreased significantly compared with $\mathrm{N}_{-} \mathrm{TiO}_{2}$ nanotubes. This may be ascribed to the heterojunction existing between $\mathrm{CdS}$ and $\mathrm{TiO}_{2}$ NTs due to $\mathrm{Cd}-\mathrm{O}$ bonds that the electrons photoinduced on the surface of $\mathrm{CdS}$ particle can transfer easily from the $\mathrm{CB}$ of CdS to that of $\mathrm{TiO}_{2}$ NTs via the well-developed hetero $\mathrm{TiO}_{2}-\mathrm{CdS}$ interface which hinders the direct electron-hole recombination [26].

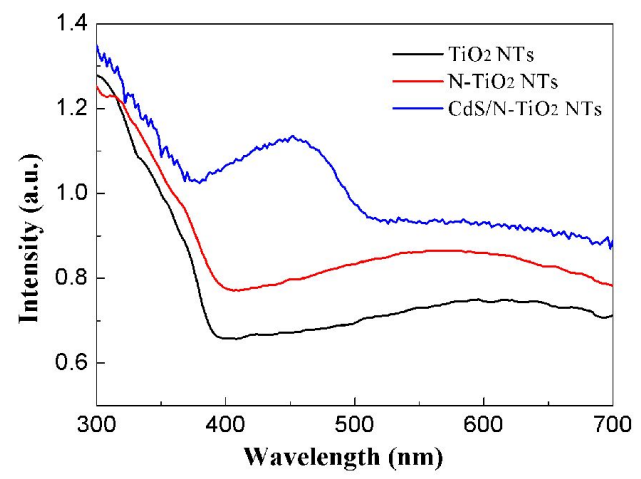

Fig. 5. UV-Vis absorption spectra of the samples.

Fig. 5 shows the UV-Vis absorption spectra of the samples. All the samples were of the same size. For the $\mathrm{TiO}_{2}$ NTs with the band-gap energy of $3.2 \mathrm{eV}$, the intrinsic absorption in the wavelength region is below $400 \mathrm{~nm}$. The absorption of $\mathrm{TiO}_{2}$ NTs in the visible region can be assigned to scattering of light caused by pores or cracks of the nanotube arrays [27]. Moreover, the characteristic absorption edge for $\mathrm{N} / \mathrm{TiO}_{2} \mathrm{NTs}$ shows a red-shift and exhibits stronger absorption. This is due to the $2 p$ orbitals of $\mathrm{N}$ atom interacting with $\mathrm{O}$ atoms, which demonstrates an effective charge transfer between the dopant and the conduction or valence band [28]. Further, $\mathrm{CdS} / \mathrm{N}-\mathrm{TiO}_{2}$ NTs sensitized with $\mathrm{CdS}$ nanoparticles, show apparent enhancement of absorption in visible region because of the surface plasmon resonance of CdS nanoparticles deposited on the $\mathrm{TiO}_{2}$ NTs which suggests that the improvement of photocatalytic efficiency in the visible region could be possible [29].

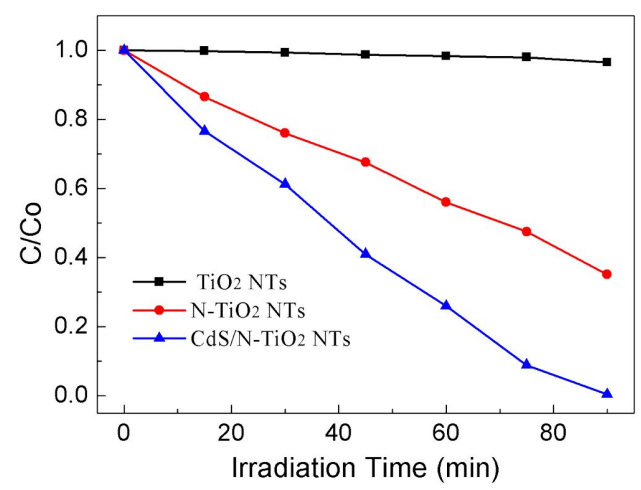

Fig. 6. Variation of MO concentration against irradiation time for $\mathrm{TiO}_{2} \mathrm{NTs}, \mathrm{N}-\mathrm{TiO}_{2} \mathrm{NTs}$, and $\mathrm{CdS} / \mathrm{N}-\mathrm{TiO}_{2}$.

The photocatalytic activity of the as-prepared samples was then investigated. Fig. 6 shows the degradation rate of MO under visible light for $90 \mathrm{~min}$ for different samples. It is obvious that the $\mathrm{TiO}_{2} \mathrm{NTs}$ and $\mathrm{CdS} / \mathrm{N}-\mathrm{TiO}_{2}$ NTs have the lowest and the best photocatalytic ability, respectively, with $3.5 \%$ and $97.6 \%$ decomposition of the MO after 90 min under visible light. The degradation rate for $\mathrm{N}_{-} \mathrm{TiO}_{2} \mathrm{NTs}$ after $90 \mathrm{~min}$ increased to $64.9 \%$ because of the enhancement of separation and efficient transferring of the photogenerated carriers after $\mathrm{N}$-doping $[30,31]$. The larger surface areas after loading of $\mathrm{CdS}$ nanoparticles enhanced the light harvesting and the separation efficiency of the electron-hole pairs. Besides, the enhanced photocatalytic properties for the $\mathrm{CdS} / \mathrm{N}$-doped $\mathrm{TiO}_{2}$ NTs in visible region may also be attributed to the facilitated formation of active radicals, LSPR effect and synergistic effect between CdS nanoparticles and $\mathrm{N}-\mathrm{TiO}_{2} \mathrm{NTs}$. Thus, the $\mathrm{CdS} / \mathrm{N}-\mathrm{TiO}_{2} \mathrm{NTs}$ demonstrated the highest photocatalytic activity towards the degradation of MO, which was consistent with the fluorescence quenching effect revealed by PL spectra in Fig. 4.

\section{Conclusions}

In summary, the nanostructure and composition of a $\mathrm{CdS} / \mathrm{N}-\mathrm{TiO}_{2}$ NTs can be designed for higher photodegradation efficiency through doping and depositing of $\mathrm{N}$ and CdS. Firstly, N-doped $\mathrm{TiO}_{2}$ NTs have been successfully 
fabricated directly by anodic oxidation of Ti foils, followed by ambient heat treatment of the $\mathrm{TiO}_{2}$ NTs pre-soaked in ammonia solution. Then, CdS nanoparticles were successfully deposited on the surface of the $\mathrm{N}-\mathrm{TiO}_{2} \mathrm{NTs}$ by the ionic layer adsorption and reaction technique. The tubular morphology of $\mathrm{TiO}_{2}$ NTs was not destroyed after N-doping, and nitrogen atoms were successfully incorporated into the interstitial sites of the $\mathrm{TiO}_{2}$ crystal lattice. In comparison with $\mathrm{TiO}_{2} \mathrm{NTs}$, the photocatalytic degradation rate of $\mathrm{CdS} / \mathrm{N}-\mathrm{TiO}_{2}$ nanotubes was enhanced by $94 \%$. It is considered that the CdS loaded N-doped $\mathrm{TiO}_{2}$ NTs exhibited a significant synergistic effect resulting in the improvement of the photocatalytic capability in degrading MO dye under visible light irradiation. In short, oxygen vacancies and surface units $\left[\mathrm{Ti}^{4+}-\mathrm{N}^{3-}\right]$ exist in the $\mathrm{N}$-doped $\mathrm{TiO}_{2}$ NTs [32]. Besides, the photogenerated electrons and holes can be separated effectively because of the chargetransfer process between $\mathrm{CdS}$ and $\mathrm{TiO}_{2}$ [33].

\section{Acknowledgements}

This work was financially supported by the National Natural Science Foundation of China (Grant No. 21403184), the Natural Science Foundation of the Jiangsu Higher Education Institutions of China (Grant No. 14KJB150025 and 15KJB430032) and the China Postdoctoral Science Foundation (No. 2014M561622).

\section{References}

[1] Wang Y., Yu J., Xiao W., Li Q., J. Mater. Chem. A, 11 (2014), 3847.

[2] Rani S., Suri P., Shishodia P.K., Mehra R.M., Sol. Energ. Mat. Sol. C., 12 (2008), 1639.

[3] An L., Wang G., Cheng Y., Gao F., Cheng, Y., J. Phys. Chem., 10 (2015), 1878.

[4] Wang B., Zhang G., Sun Z., Zheng S., Powder Technol., 262 (2014), 1.

[5] Wojcieszak D., Mazur M., Kurnatowska M., KaCZMAREK D., DomaradZKi J., KePINSKI L., ChoJnACKI K., J. Photoenergy, 3 (2014), 591.

[6] Mor G.K., Varghese O.K., Paulose M., Shankar K., Grimes C.A., Sol. Energ. Mat. Sol. C., 14 (2006), 2011.

[7] Li G., Wu L., Li F., Xu, P., Zhang, D., Li, H., Nanoscale, 5 (2013), 2118.

[8] Diwald O., Thompson T.L., Zubkov T., Yates J.T.J., J. Phys. Chem. B, 19 (2004), 6004.

[9] Huo K., GaO B., Fu J., Zhao L., Chu P.K., Rsc Adv., 33 (2014), 17300
[10] Piskunov S., Lisovisi O., Begens J., Bocharov D., ZhukovskiI Y.F., Wessel M., J. Phys. Chem. C, 119 (2015), 18686.

[11] BARAN E., YAZICI B., J. Hydrogen Energ., 41 (4) (2016), 2498.

[12] Gopinath K., Kumaraguru S., Bhakyaraj K., Arumugam A., Superlattice. Microst., 92 (2016), 100.

[13] Ampelli C., Genovese C., Lanzafame P., Perathoner S., Centi G., Chem. Eng. Trans., 39 (2014), 1627.

[14] Xiao F.X., Miao J., Wang H.Y., LiU B., J. Mater. Chem. A, 39 (2013), 12229.

[15] Ouyang J., Chang M., Zhang Y., Li X., Thin Solid Films, 7 (2012), 2994.

[16] Li D., Wang S., Wang J., Zhang X., LiU S., Mater. Res. Bull., 10 (2013), 4283.

[17] Sun L., Cai J., Wu Q., Huang P., Su Y., Lin C., Electrochim. Acta, 10 (2013), 525.

[18] Nosaka Y., Matsushita M., Nishino J., NosAKA A., Sci. Technol. Adv. Mat., 2 (2005), 143.

[19] AnsAri S.A., New J. Chem., 9 (2016), 558.

[20] Li H., HaO Y., Lu H., Liang L., Wang Y.Y., QIU J.H., Shi X.C., Wang Y., Yao J.F., Appl. Surf. Sci., 344 (2015), 112.

[21] Kim D.H., Han H.S., Cho I.S., SEONG W.M., PARK I.J., PARK J.H., Shin S., Do PARK G., PARK S., LEE S., Hong K.S., J. Hydrogen Energ., 1 (2015), 863.

[22] LiU L., Lv J., Xu G., Wang Y., Wang Y., XIE K., J. Solid State Chem., 12 (2013), 27.

[23] Liang Y., Cui Z., Zhu S., LiU Y., Yang X.J., J. Catal., 278 (2011), 276.

[24] Kim J.C., Choi J., Lee Y.B., Hong J.H., LeE J.I., YAng J.W., LeE W.I., Hur N.H., Chem. Commun., 48 (2006), 5024.

[25] Zhang, P., LiU, Y., Tian, B., Luo, Y., Zhang, J., Catal. Today, 281 (2017), 181.

[26] YU S., HU J., Li J., Int. J. Photoenergy, 12 (2014), 1.

[27] Zhang S.S., Peng F., Wang H.J., Yu H., Zhang S.Q., Yang J., ZhaO H.J., Catal. Commun., 8(2011), 689.

[28] Dang M., Zhou Y., Li H., Lv C., J. Mater. Sci. Mater. El., 1 (2012), 320.

[29] Xie Y., Kum J., Zhao X., Chao S.O., Semicond. Sci. Tech., 8 (2011), 5023.

[30] Pant B., Barakat N.A.M., Pant H.R., Park M., SAUD P.S., KIM J.W., KIM H.Y., J. Colloid Interf. Sci., 434 (2014), 159.

[31] Lan M., Zhang Y., Wang P.N., Chem. Phys. Lett., $4-6$ (2008), 341.

[32] Zhao W., Bai Z., Ren A., Guo B., Wu C., Appl. Surf. Sci., 11 (2010), 3493.

[33] Tang J.W., Zou Z.G., A, Ye J.H., Chem. Mater., 9 (2004), 1644.

Received 2016-08-12 Accepted 2018-05-02 